\title{
A behavior model for blood donors and marketing strategies to retain and attract them
}

\author{
Covadonga Aldamiz-echevarria ${ }^{1}$ \\ Maria Soledad Aguirre-Garcia ${ }^{1}$
}

Objective: analyze and propose a theoretical model that describes blood donor decisions to help staff working in blood banks (nurses and others) in their efforts to capture and retain donors. Methods: analysis of several studies on the motivations to give blood in Spain over the last six years, as well as past literature on the topic, the authors' experiences in the last 25 years in over 15 Non Governmental Organizations with different levels of responsibilities, their experiences as blood donors and the informal interviews developed during those 25 years. Results: a model is proposed with different internal and external factors that influence blood donation, as well as the different stages of the decision-making process. Conclusion: the knowledge of the donation process permits the development of marketing strategies that help to increase donors and donations.

Descriptors: Nursing Services; Blood Banks; Helping Behavior; Blood Donors; Social Marketing.

\footnotetext{
${ }^{1}$ PhD, Professor, Departamento de Economia Financiera II, Facultad de Ciencias Económicas y Empresariales, Universidad del País Vasco - Euskal Herriko Unibertsitatea, Spain.
}

Corresponding Author:

Covadonga Aldamiz-echevarria

Universidad del País Vasco - Euskal Herriko Unibertsitatea

Facultad de Ciencias Económicas y Empresariales

Departamento de Economia Financiera II

Avda. Lehendakari Aguirre, 83

48015, Bilbao, España

E-mail: covadonga.aldamiz@ehu.es
Copyright @ 2014 Revista Latino-Americana de Enfermagem This is an Open Access article distributed under the terms of the Creative Commons Attribution Non-Commercial License (CC BY-NC).

This license lets others distribute, remix, tweak, and build upon your work non-commercially, and although their new works must also acknowledge you and be non-commercial, they don't have to license their derivative works on the same terms. 


\section{Introduction}

According to the last data provided by the Spanish Federation of Blood Donors ${ }^{(1)}$, in Spain, during the year 2011, there were 234,750 new donors, $2 \%$ more than the previous year, which means that the message of solidarity and altruistic blood donation has had a positive response. The data show that, in 2011, there were 2,165,000 active donors, more than 6,000 daily transfusions, 27,500 lives saved by the exclusive effect of blood donated, and 130,000 sick or injured people who improved their health or their quality of life. Despite this spectacular result, more donors and more donations from the existing ones are required to continue the health care needed because the donations per 1,000 habitants was 38.07, almost 2 points below that which the World Health Organization considers necessary (40 donations per 1,000 habitants).

To improve the total number of donations, marketing principles can help, but they cannot consist of a direct transfer of the techniques and strategies applied in the private sector. Exhaustive knowledge of the blood donor behavior process is necessary to establish new marketing strategies that will improve the effectiveness and efficiency of blood centers.

However, there are several barriers that influence this process and they vary from one donor to another, such as fear of needles, feeling unpleasant seeing blood, fear of feeling dizzy or sick, or considering the blood donation centers or hospitals unpleasant(2). Other circumstances are previous negative experiences, or long-lasting bruising(3) or barriers, such as lack of intimacy in the donation act, schedule conflicts, and difficulties in reaching the extraction point ${ }^{(4)}$. When any of these barriers exist, the decision-making process will be longer and more complex. Not much can be done from a marketing point of view to overcome those listed first, but a good marketing strategy can help to overcome the last three.

Therefore, having in mind that the process is not always going to have the same degree of complexity, a blood donor behavior model is proposed.

The model we propose (which we will try to verify empirically in future research), is inspired on the main theories and frameworks of Consumer Behavior developed in the scientific literature from the late $1960 s^{(5-8)}$. Our proposal is mainly based on the more widely used model in the marketing literature ${ }^{(9)}$, as it has been proved especially useful in the support of decision-making on the marketing field. Also, based on the literature analyzed in this paper and our experience in the subject, we think that this is the model that better adjusts to the comprehension of blood donor behavior.

Many reasons have brought us to work in this area; some of them are personal and others scientific. Among the former, we highlight our experience in the area and that we strongly believe in the need to develop an interaction between different academic fields in order to improve society and, in this case, we thought that our knowledge of marketing could help people who work in blood banks, such as nurses and other personnel, to increase and retain blood donors. Luckily, in this research, personal and scientific reasons are joined. As qualified authors suggest(10-11), the development of scientific knowledge about consumer behavior should be complemented by an increasing application of that knowledge in today's society. Also, this macro approach will complement micro studies that have dominated consumer research over the last thirty years. All this will emerge in a better understanding of the consumption phenomena that tend to be associated less and less with the onerous purchase behavior, and more with the analysis of non-profit and social marketing exchanges. And it is precisely this area the present work fits into(11).

\section{Model of the blood donor decision-making process}

Proposition of a model

To raise awareness of the need for blood, it is important to have education programs, good communication from blood banks and health services, and the endorsement of mass media. To move from the perception of the need for blood to actual donation, organizations should increase the perceived benefits of donating and reduce its perceived costs. Most importantly, donors must be made aware that it is completely safe to donate blood, and that without generous donations people might die.

In addition, blood banks need to know the factors that affect potential donors, at the internal and external levels. Only by knowing these factors will banks be able to influence potential and actual donors.

The model we propose gathers all the factors we have considered to be decisive (Fig. 1). These concepts are often mentioned by the literature regarding the consumer behavior theory ${ }^{(5-9,12)}$. For example, with reference to the influence of attitudes on the blood donation process, one of the latest studies on this topic ${ }^{(13)}$ mentions attitude as one of the common contributors to intentions across 
donation contexts. Another very recent paper ${ }^{(14)}$ analyses the value of considering different type of attitudes (cognitive, affective and anticipated positive reactions about giving blood and anticipated negative affective reactions about not giving it) and therefore, focuses on the importance of knowing those different attitudes.

The elaboration of this model is based on three main inputs: Bibliography with models ${ }^{(5-9,12,15)}$ and references on motivations that influence the process( ${ }^{(3-4,16-18)}$, the authors' experiences in the last 25 years in over 15 NGOs with different levels of responsibility and different studies conducted in Spain since $2007^{(1-2,19-21)}$ as well as informal interviews held during the last 25 years at different extraction points.

Influencing factors in the donor decision process

As we can observe from the model, there are factors that influence the environment, such as legal issues, information about the need for blood, social norms, groups of reference and social networks, and internal factors of the blood donors. We will start by analyzing these environmental issues.

\section{Legal issues}

In Spain, as in all European countries, it is not allowed by law to pay donors for their blood. Even though, according to WHO, 26 countries still reported paying for donations in 2008, the WHO goal is for all countries to obtain blood supplies from voluntary unpaid donors by 2020 . The reason for this is that an appropriate and reliable supply of safe blood can be assured by a stable base of regular, voluntary, unpaid blood donors and because these donors are also the safest group of donors, as the prevalence of blood infections is the lowest in this group ${ }^{(22)}$.

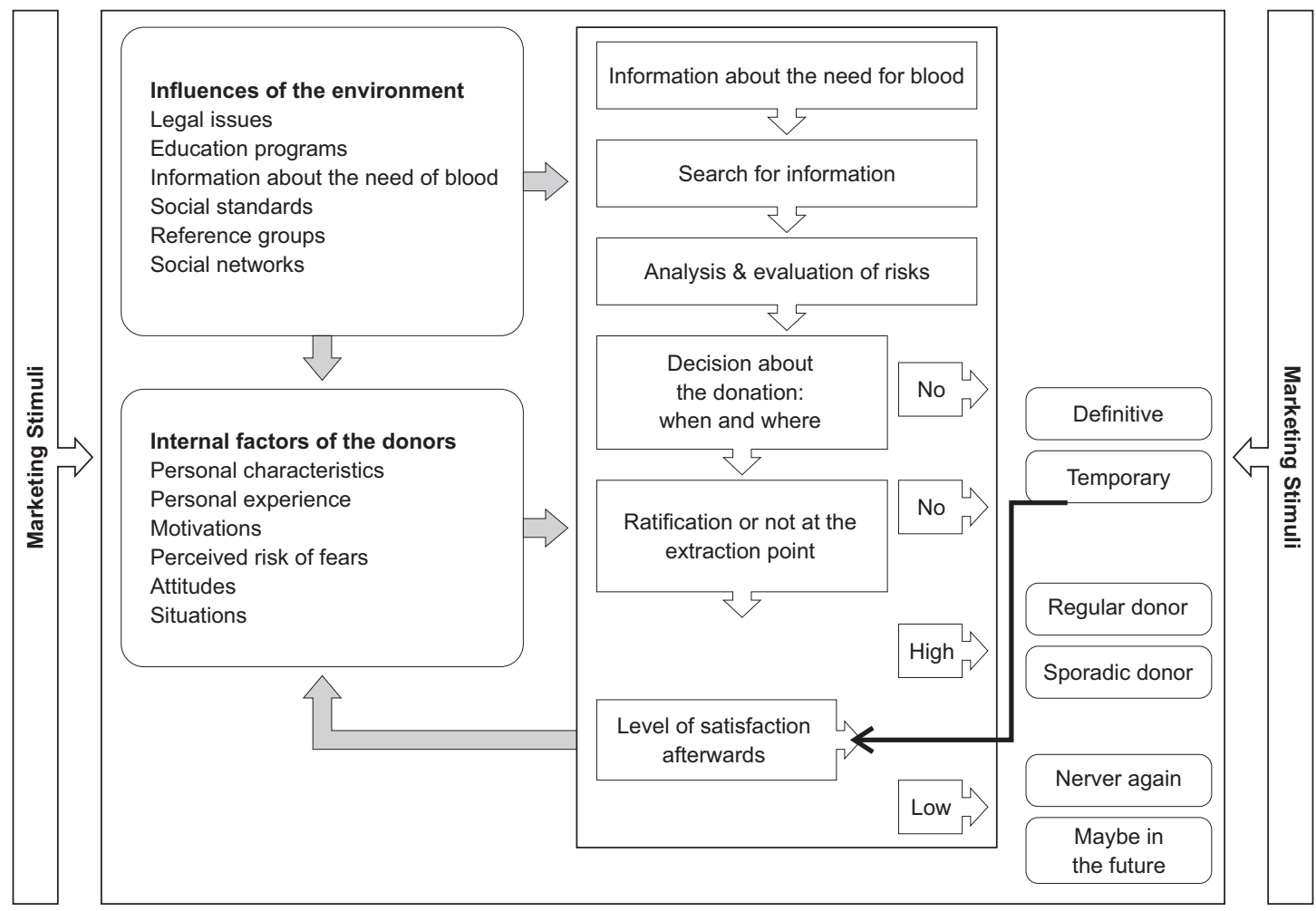

Figure 1 - Model of blood donor behavior

\section{Education on the process}

Groundless fears among non-donors - based on their misperceptions about what can happen to them if they donate (whether they can get a disease or any other fear) - has to be overcome by educational communication, convincing prospective donors of the safety of both collection practices and supply(17). A study(21) among donors and non-donors found that $46 \%$ of the interviewees did not feel well informed about the blood donation and its process, so blood centers have a necessity to educate on the safety and need of the donation. 
Information about the need for blood

This information can come through the mass media, regular donors or messages sent by the blood center. Non-donors will generally be informed by the mass media, which will mention the need for blood when required, stories about people being saved thanks to the generosity of anonymous donors, and about people who desperately need a certain type of blood of which there is shortage. This information can influence behavior and persuade regular or potential blood donors to donate blood.

According to a study ${ }^{(19)}$ from a sample of 800 donors, $18 \%$ of them discovered there was a need for blood through the media.

Another study(21), in this case a representative sample of 1,350 among the population of Spanish people, found that $40 \%$ of the respondents said they had not seen or heard anything about blood donation in the last month and, if they do not hear (or do not remember hearing) anything, it cannot influence them.

\section{Social standards}

Some people donate their blood for altruistic reasons (main reason), while others do so because of a desire or moral obligation to help others ${ }^{(2,16,18)}$. These social standards, along with transfusions which most consider as needed under certain circumstances, will facilitate the decision to donate.

\section{Reference groups}

Among the reference groups of potential donors, if there are people who have ever donated blood, or do it regularly, and they are able to satisfy all the concerns of the potential donor, the probability of donating is greater than if they do not, and these are a very important recruitment channel(18).

\section{Social networks}

This does not include the links on blood association websites to social networks, which would be part of their marketing stimuli, but what is said on those social networks, such as Facebook, Twitter, Tuenti, about the need for blood donations or the process. This is usually linked to, but can also be completely independent of the blood association's efforts.

The internal factors influencing the blood donor decision process include personal characteristics, experiences, motivations, attitudes, situations and perceived risks.

\section{Personal characteristics}

Different socio-demographic factors have been analyzed by the literature, such as the influence of gender, age and educational level on the process. In Spain, in $2011,54 \%$ of the active donors were men, whereas $46 \%$ were women ${ }^{(1)}$. This is coherent with what happens in other countries and it is not related to women being less generous, but because women tend to have less iron stores than men and cannot donate when they are pregnant, making them less eligible.

Regarding age, in Spain, 35\% of active donors were between 18 and 30 years old, $41 \%$ between 31 and 45 years, and $24 \%$ between 46 and 65 years old. The figures for young people are very good and are different from what the literature says about other countries $^{(3-4,18)}$.

To become a blood donor in Spain, there are several requirements, such as having a certain age (between 18 and 65 , or older with a medical permit), weight exceeding 50 kilograms, and being in good medical condition. To guarantee that the blood extracted is in optimal condition, an exhaustive questionnaire is passed to donors every time they make a donation. If it is a first donation, the questionnaire is even more complex. But for the blood banks, it is not only important to guarantee the safety of the blood extracted but also the health of the donor, so each time a person attempts to make a donation, they test his or her temperature, hemoglobin, blood pressure, and pulse. Because of all these tests, a significant percentage of people who go to the extracting point cannot physically make the donation. It would be interesting, from a marketing point of view, to analyze how they feel and whether they would likely go back if their problem were solved in ways in which this can be achieved and how to make them return.

\section{Personal experience}

This refers mainly to the experience of those who have donated before and, depending on that experience, the chance of them becoming a regular donor can vary. If they have experienced an unpleasant physical or psychological reaction, such as weakness, dizziness, loss of consciousness or extreme thirst, then the chance of returning is lower than if the experience was a positive one.

Sometimes, the fear of being excluded from donating is so bad that they will not try. Close to $60 \%$ of potential donors claim concerns about the possible chance of being medically disqualified; therefore, they 
do not give blood(3). The second blood donation - if the result of the first has been successful - will be much easier, and can even become a routine action.

\section{Motivations}

They vary depending on whether they are first time donors or regular donors. In the case of first time donors, the most important reason is the desire to help a relative or friend, whereas in the case of regular donors, altruism is the main reason ${ }^{(1)}$. Although altruism can be influenced by environmental factors, it is very difficult to stimulate it through marketing efforts because it is inherent to the person. What can be done through marketing stimuli is to show that a way of being altruistic is through the donation of blood, as the altruistic person may not have considered that. With the economic crisis, some people who used to give money to different charities are not able to any longer, but they can always donate blood if they fulfill the physical requirements, so it can be a way of satisfying the altruistic motivation.

Among the motivations to donate blood in Spain, according to a study based on 800 interviews ${ }^{(19)}$, the most important for almost half of the donors was solidarity, also referred to as altruism or a desire to help. The second most mentioned reason was the desire to help a family member. If there is a shortage of blood, hospitals will frequently ask patients who are to receive blood to procure volunteers to give the same amount they are going to need. This ensures the blood bank always has a supply. Other motivations shown in that study ${ }^{(19)}$ are the family tradition $(5.4 \%)$ or working or studying in the health field $(1.9 \%)$.

The literature ${ }^{(3,16-18)}$ suggests other motivations, such as strengthening of one's self-esteem, positive experiences associated with donation, social reasons (such as the influence of friends and family), general pressures to donate, personal requests, recognition, curiosity about donation, and for personal benefit (as they need to eliminate some blood to be healthier or to be tested for HIV, hepatitis or another disease-if the health team realizes this is the reason, they will tell the potential donor to have the test done elsewhere or they will make it but will not use the blood).

\section{Perceived risk or fears}

Depending on the different degree of uncertainty of the donation's consequences, the probabilities of doing it will be bigger or smaller. Thus, it has been empirically shown ${ }^{(23)}$ that the perceived risk has a direct relation to donor behavior, so that, the bigger the perceived risk, the smaller the probability of being a donor, and vice versa.

Regarding this perceived risk, after the lack of information, the second reason for not giving blood is a fear of needles, about which not much can be done from a marketing perspective other than showing other benefits.

Another perceived risk that can be counteracted with communication and education is the fear of contracting a disease. According to a study ${ }^{(21)}, 8 \%$ of the interviewees thought, erroneously, that they could get a disease by donating blood. To reduce this error, it is very important to inform, in language that is easily understood, that all donations are done with disposables, and aseptically.

Other reasons not to give include being unaware of the need for blood, and the unknown or the lack of precise information about the uses of blood. These fears are mentioned more often by non-donors or first-time donors than by regular donors and could be overcome with a good marketing strategy ${ }^{(3)}$. Perceived barriers, such as lack of intimacy, schedule conflict, and having the extraction point too far from home ${ }^{(4)}$, can also be eliminated with a good marketing strategy.

Attitudes

They are the favorable or unfavorable predispositions to act in a certain way. If the attitude is positive, the potential fears the donor might have are overcome more easily than if it is negative.

\section{Situations}

They can be the state of mind, the time the potential donor has to spare and therefore make the donation (it takes around 30-40 minutes), his or her health situation (a simple headache would not allow the potential donor to donate), what the donor is going to do afterwards (if he is going to drive, he might prefer not to donate blood at that point), the psychological conditions to make a blood donation, or whether the person they are with is going to donate blood at that moment. In Spain, the decision to donate is completely voluntary and one of the main rights of donors is not to be coerced into donating blood. So when a potential donor goes to a blood bank, the staff ensures that the volunteer is under no pressure to make the donation. If they perceive that the donor is being pressured, they encourage him or her to think about it and come back when he or she is ready. Every person who is donating has a private interview with a doctor, so, if they are with somebody who may be 
coercing them, in the personal interview the doctor will facilitate a way out of the process.

Another situation that influences is the time of the year, as in certain periods, mainly August and long weekends, more blood is needed owing to traffic accidents; therefore, there are more calls for donations.

Frequently, mobile units are sent to universities, work centers and summer recreation areas to facilitate the donation process. It is not only necessary to do this but also to know the exact date when potential donors are more likely to donate (not during exams, for example, or on the first sunny day during the summer holiday at a vacation place).

Knowing all the possible situations and their influence on donations will be useful for marketing departments, which can then take advantage of those situations that benefit blood donation and, if possible, control those that do not.

In addition to the internal and external factors already referenced, the marketing stimuli not only influence decisions directly during the decision process, as shown in fig. 1 , but also the environment and the internal factors of donors, as has been mentioned previously, and will be discussed later.

The donor decision process

Now that the different factors that influence the decision-making process have been analyzed, we will look at the different phases of this process.

The process begins with the awareness of blood needed. This phase takes place usually when a relative needs blood or when it is mentioned in the media or directly by blood banks. In the past, blood banks sent letters to regular donors saying their blood was needed, but in the last few years, they have asked donors how they would like to be contacted, and they will either send a letter, text or email. An interesting study was undertaken in the United States ${ }^{(16)}$ regarding the influence of different promotional strategies to increase repeated blood donations. They found that, apart from older people, donors prefer to receive a letter or an email rather than a phone call.

The second phase is the search for information, which can be internal and external. The internal relates to the information retained in the memory, which is what people use first. If that is sufficient, the donor usually does not go to external sources but, if it is the first donation, the attitude towards donation is weak, or the perceived risk is very big, making the search for external information very important. To make this phase easier, it is important that the blood bank or association gives information on the process and the benefits of making a donation. If the extracting process is clearly explained, as well as the benefits of giving blood not only for the people who need it but also for the donor, such as free drinks and snacks, or full blood analysis, it is easier to overcome the perceived risk and therefore get the donation. This information can be given using the communication channels of the blood bank (webpage, posters, ads, verbal communication), or trying to obtain media coverage. It can also be given at the extracting point, to help the donor's relatives or friends who accompany the donor to take the step to donate as well.

In the analysis and evaluation of risks and benefits phase, fears and other perceived risks have to be overcome, and the experiences of friends and relatives, as well as the marketing stimuli from blood centers, can help this decision. A decision also has to be made about where to donate and different factors affect that choice. The first would be past experience, either personal or that of a relative or friend, and a willingness to do it in a particular place because of the ambience (perhaps due to the nurses who work there). Another would be convenience factors, such as the closeness of the extraction point to the donor or ease of access, opening hours, and the privacy of the extracting unit.

\section{Decision}

Once the potential donor has analyzed the various places and availability to give blood, he will consider whether to carry out a donation and, if so, when and where. He must perceive that he has enough blood to share; if the potential donor feels tired - maybe due to menstruation if female - or feels it is not the most convenient moment to give, he or she might postpone the decision. So, even though the bank conducts a test to make sure the donor has enough blood, the potential donor has to decide whether to donate or not, based on the perception of his health state.

\section{Ratification or not in the extraction point}

Even at the extraction point, the potential donor can change his mind: seeing somebody feeling dizzy; the smell of the hospital; anxiety that cannot be overcome; inability to donate because he has just had an important meal; a minor heath problem; or a recent trip to certain countries. If the donor cannot donate, whether it is because he has changed his mind or because he has been denied the option (due to having a certain disease or having taken an aspirin in the last 24 
hours, for example), it is particularly important that the health staff makes the potential donor feel well so there are more chances he will return.

It is fundamental to make the donor feel well to get new donations(23), although it also depends on how the donor physically and psychologically feels afterwards.

From a marketing and health point of view, different measures can be taken to ensure the donor feels well after the donation. First, plenty of liquid and food is provided after the donation to ensure physical recovery (health issue). In the past, the food given was not particularly good; whereas, now, blood associations make the effort to supply good quality sandwiches and snacks. This was done after associations knew donors' perceptions about the food provided. It was not only a health but also a marketing issue. Now, donors often feel treated as very special, cared for, and that their desires are taken into account.

Level of satisfaction afterwards and subsequent behavior

Whether there has been a donation or not, there is always a subsequent behavior, and it is highly influenced by the level of satisfaction. The donor can either make the decision to do it again - being satisfied with the benefits of the donation and by the way blood was extracted - or not. If the donation has not yet been carried out due to a personal decision, it may not necessarily be definite. If the donor wanted to make the donation but did not pass the health check, depending on whether he would be allowed to donate in the future and how he felt about not passing the test, he may or may not wish to try again later.

The behavior that finally takes place, as well as the entire decision-making processes involved, will influence the person whose process we are analyzing in all its modifiable aspects. That is to say, on all the internal factors, but the demographic ones.

Indeed, the internal factors influence the decisionmaking process, but at the same time, the process influences those same factors. In this way, the experience influences the process, but once the person has donated blood that experience becomes bigger, and so the donation influences the subsequent decisions. Exactly the same happens with the motivations, the situations, the attitudes and the fears.

Not only will all those internal factors influence donor behavior, but also all the factors that help donation behavior to take place, such as the information about the need for blood, the social standards, the activities of reference groups and, of course, the marketing stimuli of the blood bank, which can help the process of donation, making it easier.

Marketing stimuli

Non Profit Organizations (NPOs) should develop a strong well-known identity over time(24). Thus, the marketing concept should be seen as a philosophy of action that goes beyond obtaining a donation, to one of satisfying donor needs. To do this, they must identify people who may be more willing to support their mission (market segmentation), develop an attractive image (product positioning), produce communication messages to entice them, communicate through channels that potential donors use and, in the case of blood banks, facilitate the process of donation by bringing extraction units closer, and having flexible timetables (an issue of "convenience" as it occurs in the consumer market, where products have to be easily accessible to the buyers). This is important because the process of donating blood might already be difficult to accomplish, so the easier the process for the donor, the more chances of getting their blood. And as blood is always needed, one time is not enough, so blood banks should encourage and facilitate donors to donate regularly.

In order to do that, it is important to remind donors of the need for their blood, texting them with the places and times of extractions points, and, if required, the urgent need for blood. It is important that the blood association bears in mind the last time the blood was donated, as women can only donate after four months of their last donation and men after three months.

Apart from texting, blood banks can use emails, letters, and social networks (especially effective in the dissemination of social causes) to address the donor directly, who chooses the preferred option for contact. To attract new donors, it is highly beneficial to gain media coverage, as was mentioned when describing external factors.

Among the previous sections, different possible marketing actions have been highlighted. Others would be to offer incentives, such as complete blood analysis, medical advice on health, or social appreciation through a bumper sticker, certificate, medal or diploma(2). Although the complete analysis is always done, it is not $100 \%$ accurate; therefore, it is not used as an incentive as it increases the risk of receiving infected blood from high-risk donors wanting an analysis.

It is also important to use the correct message to attract donors. As fears are the main obstacle to 
donation, messages should not focus on altruism but on reducing fears ${ }^{(25)}$.

The actions just mentioned do not pretend to be an exhaustive list of marketing actions but examples. What we have tried to show in this paper is that the elements of the donor behavior model are interrelated and that marketing strategies can help to get more donations from existing donors or from new ones.

\section{Conclusions}

This paper has analyzed and proposed a model to explain the decision-making process of blood donors in order to help blood centers, and therefore nurses and other professionals, with their blood donor uptake strategies. The main conclusions of the paper are that to increase the amount of donations, it is very important to know precisely the donor's decision-making process because, even if there is a strong motivation to help others, the blood donation act is invasive and, during any of the phases of the process, can suddenly be interrupted. The model proposed has different inputs: external and internal factors, the donation process, and the marketing stimuli that influence all of them and at the same time is affected by it. That is why all the inputs are interrelated in the model. The external factors that affect the donation process are legal issues, education programs, information about the need for blood, social standards, reference groups and social networks. The internal factors influencing the blood donor decision process include: the personal characteristics, personal experiences, motivations, attitudes, situations and perceived risks. Among the motivations to donate blood in Spain, the vast majority does it for solidarity or altruism (45\%), followed by a member of the family in need $(19.8 \%)$.

Extensive knowledge of the blood donor behavior process is necessary to establish new possible marketing of and also to abandon others that might upset donors, such as asking for blood before they are allowed to give it according to health issues (three months for men and four for women).

And, finally, the knowledge of the different phases and influencing factors on the blood donation process will facilitate the best possible use of marketing strategies to get blood and therefore help people who need it.

The main limitation of this model is that it has to be validated empirically because it is just a theoretical model, as was mentioned earlier.

\section{References}

1. Federacion Espanola de Donantes de Sangre. Datos estadisticos de la donacion de sangre en Espana [Internet]. 2013 [acesso 4 jun 2013]. Disponível em: http://www.donantesdesangre.net/

2. Martín-Santana JD, Beerli-Palacio A. Intention of future donations: a study of donors versus non-donors. Transfusion Med. 2013;23:77-86.

3. Gillespie TW, Hillyer CD. Blood donors and factors impacting the blood donation decision. Transfusion Med Rev. 2002;16(2):115-30.

4. Godin G, Conner M, Sheeran P, Bélanger-Gravel A, Germain $M$. Determinants of repeated blood donation among new and experienced blood donors. Transfusion. 2007;47:1607-15.

5. Engel JF, Kollat DT, Blackwell RD. Consumer behavior. New York: Holt, Rinehart \& Winston; 1968.

6. Engel JF, Blackwell RD, Miniard PW.Consumer Behavior, Chicago: The Dryden Press. 1986.

7. Howard JA, Jagdish N, Sheth, JN. The Theory of Buyer Behavior. New York: Wiley; 1969.

8. O'Shaughnessy J. Explaining Buyer Behavior: Central Concepts and Philosophy of Science Issues. Oxford: University Press; 1992.

9. Engel JF, Blackwell RD, Miniard PW. Consumer Behavior. 10th. ed. Boston: Thomson/South-Western International; 2005.

10. Richins ML, Consumer Behavior as a Social Science. Adv Consum Res. 2001;28:1-5.

11. Ruiz de Maya S. El comportamiento del consumidor en marketing. Del método científico a su posición en la empresa. Cuad Adm. 2001;17(26):35-57.

12. Mollá A. Comportamiento del consumidor, Barcelona: Editorial UOC; 2006. 240 p.

13. Hyde, MK, Knowles, SR, White, KM. Donating blood and organs: using an extended theory of planned behavior perspective to identify similarities and differences in individual motivations to donate. Health Educ. Res. 2013;28(6):1092-104.

14. Conner M; Godin G, Sheeran P, Germain M. Some Feelings Are More Important: Cognitive Attitudes, Affective Attitudes, Anticipated Affect, and Blood Donation. Health Psychol. 2013;32(3):264-72.

15. Aldamiz-echevarria C, Aguirre-Garcia, MS. Analysis and proposal of a donor behavior model applied to development organizations in Spain. Proceedings of the 3rd Annual International Conference on Enterprise Marketing and Globalization; 2013. p. 37-46. 
16. Glynn SA, Kleinman SH, Schreiber GB, Zuck T, Combs SM, Bethel J, et al. Motivations to donate blood: demographic comparisons. Transfusion. 2002; 42:216-225.

17. Hupfer ME, Taylor DW, Letwin JA. Understanding Canadian student motivations and beliefs about giving blood. Transfusion. 2005;45:149-61.

18. Misje AH, Bosnes V, Gasdal O, Heier, HE. Motivation, recruitment and retention of voluntary non-remunerated blood donors: a survey-based questionnaire study. Vox Sang. 2005;89:236-44.

19. Direcció de Màrqueting, Banc de Sand y Teixits. Resultats de l'estudi de mercat Motivacions I satisfacció del donant de sang [Internet]. [acesso 4 jun 2013]. Disponível em: http://www.donarsang.gencat.cat/media/upload/ pdf/com_sou_els_donants_de_sang_motivacions_ satisfaccio_editora_7_6_1_editora_8_12_1.pdf

20. Colina N, Perozo H, Vargas E, Matos C. Factores motivacionales de las personas para ser donantes de sangre [Internet]. Hospital Central "Antonio María Pineda" Barquisimeto, Lara. Hematologia y Hemoterapia. 2011 Marzo [acesso 4 jun 2013]. Disponível em: http://www. portalesmedicos.com/publicaciones/articles/3115/1/ Factores-motivacionales-de-las-personas-para-serdonantes-de-sangre

21. OCU - Organización de Consumidores y Usuarios. Donacion de sangre: Urge mejorar la informacion. [Internet]. 2008 [acesso 4 jun 2013]. Disponível em: http://www.ocu.org/nt/nc/nota-prensa/donacion-desangre-urge-mejorar-la-informacion392844/stampa 22. WHO, Blood Transfusion Safety [Internet]. [acesso 4 jun 2013]. Disponível em: http://www.who.int/ bloodsafety/voluntary_donation/en/

23. Gallagher K, Weinberg CB. Coping with success: new challenges for nonprofit marketing. Sloan Manage Rev. $1991 ; 33(1): 27$.

24. Maynard WG. Marketing for Non-profit Organizations, Concept Marketing Group [Internet]. 2008 [acesso 5 jul 2012]. Disponível em: http://www.marketingsource. com/articles/view/2101.

25. Cacioppo JT, Gardner WL. Emotion. Annu Rev Psychol. 1999;50:191-214. 